\title{
Atmospheric Moisture Sources Of Drought And Wet Events During 1979-2019 In The Three-River Source Region, Qinghai-Tibetan Plateau
}

Rong Liu ( $\sim$ rliu@lzb.ac.cn)

Chinese Academy of Sciences

Xin Wang

Zuoliang Wang

\section{Research Article}

Keywords: The three-river source region, water vapour transport, SPI, Lagrangian model, drought index

Posted Date: February 21st, 2022

DOI: https://doi.org/10.21203/rs.3.rs-1298453/v1

License: (c) (1) This work is licensed under a Creative Commons Attribution 4.0 International License. Read Full License 


\section{Abstract}

The soil moisture observation data from the Qinghai-Tibetan Plateau permafrost and alpine wetland (PAW) monitoring network and from the National Centers for Environmental Prediction Final (NCEP-FNL) from 1989 to 2019 were adopted to drive the Lagrangian backward trajectory model to simulate the water vapour transportation paths and source regions to the three-river source region during dry and wet episodes. The results showed that the water vapour transport paths mainly came from the land and ocean in the west during the extreme drought episodes based on the standardized precipitation index (SPI), including the northern African continent, the eastern European plains, and the mid-latitudes of the Atlantic Ocean. The water vapour source regions were mainly concentrated in the Kashmir region, northeast India and southern Motuo on the Qinghai-Tibet Plateau. When the SPI indicated an extremely wet state, the transport mainly occurred to the east and south, including the Pacific Ocean and the South China Sea, where water vapour entered the mainland from East/South China, passed through the Yangtze River Basin, and finally reached the three-river source region from east or south of the Qinghai-Tibet Plateau, while the water vapour from the Indian Ocean and Arabian Sea passed through the Indian Peninsula and the Bay of Bengal and entered the three-river source region from the western and southern sides of the Qinghai-Tibet Plateau.

\section{Introduction}

The three-river source region is in the interior of the Qinghai-Tibet Plateau. As the birthplace of the Yangtze River, Yellow River and Lancang River, this place provides a total of 60 billion cubic metres of water to downstream areas each year, which is why this area is known as the reservoir of China (Li et al., 2019; Zhang et al., 2017). With the unique topography, landform and climate, the three-river source region features many plateau lakes, glaciers and alpine wetlands, marking it as one of the most important water resource accumulation and regulation areas in China (Shen et al., 2021). However, in the past several decades, due to the impact of climate change and human activities, the snow-capped mountains and glaciers there have retreated, lakes and wetlands have shrunk or even dried up, the area of water and soil loss has expanded, desertification and grassland degradation have become increasingly aggravated, and water conservation capacity has declined sharply ( $\mathrm{Li}$ and Xiao, 2020). According to statistics, taking the total area experiencing disasters as an example, drought disasters strike the three-river source region most, with a proportion of $38 \%$, which exceeds floods, hail, frost, pests and snow disasters, and the increase in drought disasters in the central and northern parts show a frequent trend, with an increasing rate of approximately $8.35 \times 10^{4} \mathrm{hm}^{2} / 10 \mathrm{a}$ (Wu et al., 2011).

Global warming is regarded as an indisputable fact, so monitoring drought events has become a hot spot for scientists worldwide. The drought index can represent drought characteristics and be used to assess drought events effectively. Thus, this index can be used as a key indicator for drought monitoring. The standardized precipitation index (SPI) is regarded as the most representative and widely used drought index (Raziei, 2021). Only precipitation data are required for drought condition assessment. The calculation process is simple, and the time scale is flexible, but the impacts on soil evaporation and 
temperature on drought are not considered (Kalisa et al., 2020). The SPI is calculated based on observational data from meteorological stations, but observational data of the Qinghai-Tibet Plateau are scarce, which makes it difficult to fully describe the regional drought characteristics. On the other hand, in addition to the drought index calculated based on meteorological elements, the anomaly of soil moisture can also effectively reflect the actual dry-wet condition of the land surface and be used to test the drought index or serve as an evaluation standard for the applicability of various drought indices (Hogg et al., 2013; Halwatura et al., 2017). The soil moisture anomaly percentage index (SMAPI) defined by Wu et al. (2011) can reflect the occurrence, development process and severity of actual droughts and better represent historical drought events. However, due to the significant spatial variability in soil moisture, even though the soil moisture observation at each site is accurate, its representativeness and typicality are difficult to assess (Liu et al., 2019).

Water vapour transport is an essential factor leading to regional droughts and floods(Xu et al., 2020). Many studies have focused on the characteristics of water vapour transport on the Qinghai-Tibet Plateau based on isotope analysis, reanalysis data sets, and numerical simulation of atmospheric models. Xu et al. (2002) proposed that the "large triangle" of water vapour transport on the plateau was the main cause of abnormal drought and floods in China and East Asia. Bothe et al. (2011) discussed the relationship between drought and large-scale circulation on the Qinghai-Tibet Plateau. They believed that extreme drought and wet events on the Qinghai-Tibet Plateau were related to anomalous circulation in the North Atlantic and Europe together with the wave train across Eurasia, adjusting the flow fields in the northern and eastern plateau through anticyclone-cyclone dipole and thereby inhibiting the water vapour transport from the Bay of Bengal to the plateau. Zhang et al. (2017) believed that the water vapour carried by the westerly jet and the Indian monsoon caused precipitation on the Qinghai-Tibet Plateau and analysed the characteristics of the two water vapour transport paths.

The Lagrangian method-based flexible particle dispersion model (FLEXPART) has been applied to water vapour transport research. This model overcomes the deficiencies, including the lack of understanding of the Lagrangian method (such as dynamic trajectory, the assumption of how the surface evaporation is distributed in the entire atmospheric column) and its limitations of only tracking the trajectory of the air masses qualitatively, but the water vapour evaporation and dissipation of air masses cannot be quantitatively determined during movement (Sodemann et al., 2008; Li et al., 2020). Gimeno et al. (2012, 2013) discussed the oceanic and continental source regions of terrestrial precipitation on a global scale. Chen et al. (2012) used the Lagrangian backward trajectory model to simulate the paths and potential source regions of water vapour transport on the Qinghai-Tibet Plateau during 2005-2009, indicating that the water vapour in the low-latitude ocean carried by the Indian monsoon was the main water vapour source of the Qinghai-Tibet Plateau. Sun and Wang (2014) used the Lagrangian backward trajectory model to study the water vapour source and transport characteristics of China's semiarid grassland in cold and warm seasons. Salah et al. (2018), based on the FLEXPART trajectory model and with the SPEI as the drought assessment method, discussed the abnormal characteristics of water vapour transport in two severe drought cases in the history of Fertile Crescent. Zhao et al. (2018) traced the path of water 
vapour transport from the Qinghai-Tibet Plateau to the Yangtze River based on the model and analysed the influence of plateau convection on heavy rain in the Yangtze River Basin.

The three-river source region is a typical area affected by the mid-latitude westerlies and the South Asia monsoon. The northerly airflow from the north of the plateau and the southerly airflow from the south form a convergence zone in the source region of the three rivers. This flow field makes the three-river source region an area with active weather systems, such as low humidity and shear lines. These lowvalue systems provide power for water vapour convergence (Sun and Wang, 2018). On the other hand, the decrease in precipitation caused by abnormal water vapour transport both in the source region itself and outside is an important cause of drought. Drought in the three-river source region will not only adversely affect local production, life, and social development but will also have a serious impact on the security of water resources in the middle and lower reaches of the three major rivers, directly threatening the entire Yangtze and Yellow River basins and even Southeast Asia (Dong et al., 2016).

Understanding the dry-wet evolution process of the three-river source region, especially abnormal water vapour transport corresponding to regional drought, has important practical significance for a deep understanding of the land surface process in the source region. Most of the investigations are based on the dry-wet evolution characteristics of the land surface in the three-river source region, that is, describing the intensity, scope, and starting and ending times of drought events, especially extreme drought events. However, few studies have focused on the physical process of drought in the three-river source region from the perspective of atmospheric water resources.

Considering the uncertainty of the land surface dry-wet evolution in the three-river source region and the complex water vapour sources, this work started from the drought index of the source region and based on the observation data from the Qinghai-Tibetan Plateau permafrost and alpine wetland (PAW) monitoring network located in the three-river source region from 2008 to 2018 , the applicability of the SPI in the three-river source region was assessed and evaluated. Then, the time series and drought intensity based on the SPI from 1988 to 2020 were obtained. Subsequently, the Lagrangian backward trajectory model was used to quantitatively evaluate the relationship between the drought event and the water vapour transport under different drought events corresponding to different drought indices. Finally, the anomaly of the water vapour source during the extreme drought event was extracted, and the intensity of the source region evaporation was analysed. The results of the research not only helped to better understand the characteristics of the water vapour transport and evaporation source in the three-river source region but also helped to understand the characteristics and mechanism of the land surface drywet evolution process corresponding to the water vapour transport.

\section{Data And Methodology \\ 2.1 Study area}


The study area is in the eastern part of the Qinghai-Tibet Plateau (Fig. 1), which is the source region of the Yellow River, Yangtze River and Lancang River (Liu et al., 2021). This area has the largest wetland with the most plateau peat swamps in China. The terrain of this area is high in the west and low in the east, sloping from northwest to southeast. The altitude is between $3,300 \mathrm{~m}$ and $4,806 \mathrm{~m}$, with an average altitude of 3,600 m. Affected by the Qinghai-Tibet Plateau and continental monsoon climate, the area is cold and humid, with rainy summers and dry winters. The temperature and precipitation both show a decreasing trend from southeast to northwest. The annual average precipitation is $505 \mathrm{~mm}$, and the annual average temperature is $2^{\circ} \mathrm{C}$ (Kirillin et al., 2017).

\subsection{Data and methodology}

\subsubsection{Observational data of soil moisture}

The observational data of soil moisture come from the PAW monitoring network in the eastern part of the Qinghai-Tibet Plateau (Fig. 2). The networks were established in 2008. There are two PAW networks, one is in the middle of the study area $\left(34^{\circ} 20^{\prime} \mathrm{N}-36^{\circ} 00^{\prime} \mathrm{N} ; 96^{\circ} 00^{\prime} \mathrm{E}-97^{\circ} 00^{\prime} \mathrm{E}\right)$ and one is in the eastern $\left(33^{\circ} 30^{\prime} \mathrm{N}-\right.$ $34^{\circ} 15^{\prime} \mathrm{N} ; 101^{\circ} 38^{\prime} \mathrm{E}-102^{\circ} 45^{\prime} \mathrm{E}$ ) of the study area. The monitoring networks consist of 8 and 25 stations, which are set up on the underlying surfaces of typical valleys, rivers, wetlands, grasslands, and bare lands, with an area of approximately $40 \mathrm{~km} \times 80 \mathrm{~km}$. The network can monitor the soil temperature and moisture of different slopes and different soil layers with a range of 5-80 $\mathrm{cm}$ below the ground surface. The monitoring interval is 15 minutes.

\subsubsection{Reanalysis data}

The reanalysis data used were the final analysis field data National Centers for Environmental Prediction Final (NCEP-FNL) provided by the NCEP of the United States, and these data included meteorological data, such as humidity, temperature, pressure, air density, and boundary layer height. The spatial resolution was $1^{\circ} \times 1^{\circ}$, the temporal resolution was 6 hours, and the data were collected at 00:00 (Universal Time, the same below), 06:00, 12:00, and 18:00. In the vertical direction, there are 26 layers (1000-10 $\mathrm{hPa}$ ), and the FNL data have added 5 layers of $1,2,3,5$, and $7 \mathrm{hPa}$ in the vertical direction since 12:00 on May 11,2016 . FNL data have relatively high resolution and incorporate many observational data and satellite retrieval data, which is why they are widely used in numerical models and diagnostic analyses of weather and climate. Huang and Gao (2018) used FNL data to analyse the measured data from 753 stations in China and pointed out that FNL surface temperature data can better reflect the surface temperature, but the data of some sites were lower than the measured data. Dong et al. (2017) compared the horizontal wind field, temperature, and relative humidity from FNL in the eastern and downstream areas of the Qinghai-Tibet Plateau with sounding data and pointed out that the average wind field and temperature were consistent with the sounding data, while the average relative humidity showed a larger deviation from the sounding data. In summary, FNL reanalysis data are used as the environmental field in this study, driving the backward simulation in the FLEXPART model.

\subsubsection{Precipitation and temperature data}


When calculating the drought index the SPI, the annual average air temperature and precipitation from 1968 to 2017 from the Meteorological Station (site number: 56074) in the "Daily Data Set of Surface Climate in China (V3.0)" provided by the National Meteorological Data Service Center (http://data.cma.cn/) were used, where the air temperature was the daily average temperature with an accuracy of $0.1^{\circ} \mathrm{C}$. The precipitation was the accumulated precipitation in 24 hours from the previous day at 20:00 to the next day at 20:00, with an accuracy of $0.2 \mathrm{~mm}$. Quality control was performed to eliminate abnormal values before using the data. The monthly average temperature and monthly cumulative precipitation were used for the SPI calculation at different time scales.

\subsection{Methodology}

\subsubsection{FLEXPART model}

FLEXPART is a Lagrangian particle transport and dispersion model that was originally adopted to simulate the dispersion of pollutants, but it has now been increasingly used in air transport simulation and analysis. This model can simulate the air parcel trajectory of the research area, track its threedimensional position (latitude, longitude and vertical height), and simulate the air transport process through changes in humidity, temperature, air density and other parameters during movement (Fremme and Sodemann, 2019). The model has two modes: forward process and backward process. The former is used to simulate the dispersion process of matter emitted by emission sources, while the latter is used to simulate the source of matter in the research area and its subsequent transport process after being discharged. In this research, FNL data were used as an input to drive the model, and the integration time step of the model was set at $6 \mathrm{~h}$; the "area packing" technology was used to evenly divide the air in the research area into 2 million air parcels. The scope of the emission area was $33^{\circ} \mathrm{N}-34.5^{\circ} \mathrm{N}, 101^{\circ} \mathrm{E}-102.5^{\circ} \mathrm{E}$, with the vertical height set from $3000 \mathrm{~m}$ to $16000 \mathrm{~m}$. The backward simulation time range was set at 10 days, that is, backward tracking 10 days since the particle was released, which was the average retention time of water vapour in the air (Trenberth, 1999). After the model ran, it output the three-dimensional position of each air parcel during the simulation process and obtained physical information, such as potential vorticity, specific humidity, and air density, during the simulation process through spatial interpolation of the reanalysis data (Chen et al., 2012).

\subsubsection{Soil moisture abnormal percentage index (SMAPI)}

As a statistic, the SMAPI can be used to analyse the soil moisture characteristics in different weather types and different time periods. Therefore, the SMAPI was used to evaluate the applicability of various drought indices in the research area. The SMAPI uses the mean value of soil moisture observed in the same period $(\theta)$ as the climatically optimal value of the soil moisture content in the research area during the period, that is, taking the average soil moisture of the same month in the time series as the climatic optimum of the period in the year, thus eliminating the influence of seasonal changes on soil moisture. The ratio of the difference between the current soil moisture content $(\theta)$ and the climatically optimal soil 
moisture content of the same period $(\theta)$ to the climatically optimal soil moisture content $(\theta)$ is taken as the SMAPI, and the calculation formula is shown in (Liu et al., 2019)

$$
S M A P I=\frac{\theta-\theta}{\theta} \times 100 \%
$$

1

The soil moisture adopted in the SMAPI is the weighted average, that is, the soil moisture at different depths finally obtains a weighted average based on thickness. To obtain the characteristics of the soil moisture at different depths, in addition to the SMAPI, this research also calculates the SMAPI of the soil at different depths, SMAPI-t ( $\mathrm{t}$ represents different depths; for example, SMAPI at $0.05 \mathrm{~m}$ is SMAPI- 0.05).

\subsubsection{Drought index}

SPI was first proposed by Mckee et al. (1993), and its calculation process requires monthly accumulated precipitation data in a time series of 30 years or longer. If the precipitation sequence complies with the $\Gamma$ distribution, the precipitation on a given time scale is $\mathrm{x}$, its $\Gamma$ distribution probability density function is $p(x)$, and the cumulative probability of a given time scale is $G(x)$. Since the gamma equation does not include the probability when the precipitation is 0 , it is assumed that the probability of the precipitation being 0 is $q$, so the final cumulative probability $H(x)$ of a given time scale is

$$
G(x)=\int_{0}^{x} p(x) d x
$$

2

$$
H(x)=q+(1-q) G(x)
$$

3

To eliminate the difference in the temporal and spatial distribution of precipitation and achieve comparability on different temporal and spatial scales, a standardized $\mathrm{H}(\mathrm{x})$ is used to calculate the SPI. This study uses the standard calculation program (http://greenleaf.unl.edu/downloads/SPI.zip) issued by the University of Nebraska-Lincoln to calculate the SPI at different time scales $(k=1,3,6,9,12$, and 24), and the SPI at time scale $\mathrm{k}$ is recorded as SPI-k. For example, when the time scale is 3 months, it is represented as SPI-3. For the wet-dry level corresponding to the SPI value, -0.5 represents a normal state, while more than 2.0 is extremely wet and less than -2.0 is extremely dry (Wu, et al., 2011).

\subsubsection{Water vapour evaporation source}

This research is based on the Lagrangian backward trajectory model and tracks the area where the moisture content in the air parcel changes based on the change in specific humidity when the air parcel moves. First, we suppose that the moisture content change during the movement of the air parcel is 
caused by air parcel precipitation and land surface evaporation, wherein land surface evaporation causes the moisture content in the air parcel to increase and air parcel precipitation causes the water content to decrease. Therefore, for the water budget of a single air parcel (Chen et al., 2013),

$\mathrm{e}-p=m \frac{\Delta q}{\Delta t}$

where $e$ is the water evaporated into the air parcel from the land surface in a unit of time step ; $p$ is the water lost through air parcel precipitation in a unit of time step ; and is the change in specific humidity. Assuming that the three-dimensional air of a region with an area of $\mathrm{A}$ is composed of $\mathrm{N}$ air parcels with relatively even mass, the water budget equation of a single air parcel can be used to derive the average water budget equation for the entire region:

$E-P=\frac{\sum_{i=1}^{N} m \frac{\Delta q}{\Delta t}}{A}$

$\mathrm{E}$ and $\mathrm{P}$ are the regional average land surface evaporation and air parcel precipitation, respectively. When the value of $\mathrm{N}$ is large enough, the calculated result is considered accurate enough. According to formula (5), the change in the specific humidity during the air parcel movement is used to determine the change in the water content in the air parcel to determine whether the region is the water vapour source; that is, whether the region is the water vapour source is determined by the calculated result. For example, when the result of E-P is positive, the land surface evaporation of the region is greater than the air parcel precipitation, and the water in the air parcel is replenished, which is indicative of a water vapour source. Conversely, when E-P is negative, the land surface evaporation is less than the air parcel precipitation, and the moisture in the air parcel is reduced, which is indicative of a water vapour sink. In addition, the intensity of a water vapour source or sink can be judged by the value of E-P. The advantage of this method is that it uses a concise method to explain the balance of atmospheric moisture without considering its convergence effect (Sun et al., 2014). However, it should be noted that formula (5) calculates the entire E-P, not E or $\mathrm{P}$ alone. In addition, this method only considers the increase in the moisture content of the air parcel below the height of the atmospheric boundary layer to make sense because water vapour evaporation is a process occurring at the land surface, while the increase in moisture above the height of the atmospheric boundary layer may be caused by factors, such as convection, re-evaporation of precipitation, and calculation errors (Chen et al., 2012).

\section{Results}

\subsection{SPI-based drought characteristics analysis}

This research calculated the SMAPI of different soil depths from June 2008 to June 2017 based on the observational data of the soil moisture observation network and the SPI of different time series based on the observational data of the National Meteorological Data Service Center during the same period (Fig. 3). 
Fig. 3 shows that the SPI generally has the same trend as the SMAPI at different depths. The two most obvious processes from extreme drought (SPl<-2.0) to extreme wetness (SPI>2.0) occurred from December 2010 to December 2012 and from January 2015 to December. According to the correlation coefficient and the significance test (Table 1), for the SMAPI at $0.05 \mathrm{~m}$ and $0.10 \mathrm{~m}$ and the time scale $\mathrm{k}=6$, the SMAPI and SPI showed the strongest correlation, with correlation coefficients reaching 0.47 and 0.48 , respectively. This study demonstrates that the SPI can well describe the drought characteristics of the three-river source region, and the SPI value at the time scale $k=6$ was selected for analysis with a time series of 30 years.

Table 1

Linear relationship between the SPI and SMAPI at different depths

\begin{tabular}{|lllllll|}
\hline Index & SPI-1 & SPI-3 & SPI-6 & SPI-9 & SPI-12 & SPI-24 \\
\hline SMAPI-0.05 & 0.40 & 0.42 & 0.47 & 0.41 & 0.34 & 0.30 \\
\hline SMAPI-0.10 & 0.33 & 0.39 & 0.48 & 0.37 & 0.36 & 0.37 \\
\hline SMAPI-0.20 & 0.24 & 0.28 & 0.34 & 0.35 & 0.30 & 0.47 \\
\hline SMAPI-0.40 & 0.22 & 0.33 & 0.30 & 0.32 & 0.24 & 0.38 \\
\hline SMAPI-0.80 & 0.13 & 0.17 & 0.18 & 0.28 & 0.33 & 0.39 \\
\hline
\end{tabular}

Figure 4 shows the changes in the SPI from 1988 to 2019, from which the SPI fluctuated over 30 years. The oscillation period was 3-8 years, and the maximum amplitude was between -2.22 and 2.44 , indicating that the research area experienced a cycle of drought-wetness-drought every 3-8 years. The SPIs of -2.22 (March 2003), 2.44 (July 2012) and 0.09 (April 2008) were selected as the extremely dry, extremely wet and normal states, respectively, to analyse the pathways and sources.

\subsection{Moisture transport pathway}

To further analyse the trajectory of air parcel movement in the target region under different dry-wet soil episodes, this research extracted three different periods of extreme drought, normal state, and extreme wetness from 1999 to 2019 and analysed the changes in air water resources from the perspective of water vapour transport. Selecting March 2003 as the extremely dry period, April 2008 as the normal period, and July 2012 as the extremely wet period, the FLEXPART mode was used to carry out backward trajectory tracking of water vapour arriving in the target region. To display the trajectory route clearly, the cluster number is 50 . The small black box in the figure represents the end of the backward trajectory (that is, the starting point of the water vapour transport trajectory), and different colours of trajectory lines represent the specific humidity change in the particle during the movement: the warm colour represents that the particle is supplemented by water vapour brought by local evaporation during the movement, and the cool colour represents the reduction in water vapour caused by precipitation of the particle during movement.

Based on the SPI, Fig. 5 shows the backward trajectory of water vapour transport in extremely drought (Fig. 5a), normal (Fig. 5b), and extremely wet (Fig. 5c) events. Under extremely dry conditions, the water 
vapour transport routes were mainly based on the land and the ocean in the west, including the northern part of the African continent, the East European Plains, and the mid-latitude waters of the Atlantic Ocean, passing through the mid-latitude Eurasian continent and entering the three-river source region from west of the Qinghai-Tibet Plateau. The starting point of the air parcel movement was mainly 20-60 degrees north latitude. During the movement, the specific humidity decreased at approximately 20 degrees north latitude and increased at approximately 40 degrees north latitude. Under normal conditions with a drought index of approximately zero, the water vapour paths mainly came from the west and the north. Unlike the path in extreme drought, the air parcel passed through the southern part of the Western Siberian Plain and entered the northern part of the three-river source region, and the starting point of the air parcel movement was mainly concentrated at approximately 20 and 60 degrees north latitude. The specific humidity decreased when the air parcel moved to approximately 20 degrees north latitude and increased when it approached 60 degrees north latitude. In addition, sporadic water vapour was transported along the northern part of the Indian Ocean, crossing the Himalayas and entering the threeriver source region from the southern Tibetan Plateau. The water vapour transport pathways in the east were basically negligible. In the extremely wet state, in addition to the western land, the water vapour was mainly from the Indian Ocean and the Arabian Sea by way of the Indian Peninsula and the Bay of Bengal, entering the three-river source region from the southeast and southwest sides of the Qinghai-Tibet Plateau; the water vapour from the Pacific Ocean, South China Sea, Yellow Sea and East China Sea entered the Chinese mainland from East/South China, passing through the Yangtze River Basin, and finally reaching the three-river source region from east or south of the Qinghai-Tibet Plateau. During the process of particle movement, the spatial distribution showed a decrease in specific humidity.

Figure 5 indicates that there were fewer trajectories starting in the Atlantic Ocean during the wet period, and the trajectory density on the north side was significantly lower than that on the south and east sides. The water vapour was mostly located in the south branch and east branch paths, and the starting point appeared further south than in the dry period, concentrated in the East China Sea and Taiwan Island area. The distribution of the east branch paths was also more intensive. Therefore, the effect of the north branch path was weaker than that of other periods, while the east branch path was greatly reduced during the dry and normal periods, and the starting point of the trajectory in the South China Sea and the East China Sea was greatly reduced, which can be basically ignored. Water vapour replenishment (the area of warm colour trajectories) was also mostly located on the north branch paths. Comparing the trajectories of the wet period and the dry period, the water vapour recharge distributed on the south branch and the east branch paths during the wet period was obviously stronger than that in the dry period, while the water vapour recharge distributed on the north branch trajectory showed the opposite characteristic. Therefore, the drought index of the research region showed that the water vapour transport during the extremely wet period was dominated by the south branch and the east branch, while the north branch dominated during the extremely dry period. The trajectory shows that when the drought index was in the normal state, the main transport path was not much different from that in the dry period, and both can be divided into two paths - the north branch and the west branch. However, different from the wet period and the dry period, during the normal period, the trajectory of the air parcel was more northerly, and the 
density of the north branch path was greater than that of extremely wet and extremely dry periods. Therefore, the path of the north branch in the normal period played a greater role than in other periods, and the performance of the south branch path was weaker than that during the extremely wet period.

At $500 \mathrm{hPa}$ (As shown in Fig. 6a), the anticyclone dominates over the Arabian Sea. The Asian African subtropical jet is in the south of the Iranian Plateau and the Qinghai-Tibet Plateau. Combined with the spatial distribution of vapor flux and divergence (Fig. 6b), the water vapor in the southeast of the QinghaiTibet plateau is mainly carried by both the anticyclone over the Arabian Sea and the Asian African subtropical jet. As seen in Fig. 6c, the South Asian anticyclone dominates over the South Asian continent and the Qinghai-Tibet Plateau. The circulation shows a divergent flow in the east of the plateau, associated with the vertical upward movement. The South Asian summer monsoon and the Southwest monsoon leads the water vapor transported from the Bay of Bengal to the east of the plateau (Fig. $6 \mathrm{~d}$ ). The water vapor convergence associated with the vertical upward movement contributes to precipitation in this area.

As to the extreme drought event, the south-west monsoon winds are weak, carrying less water vapour and decreasing the vapor content in the source area. The convergence occurs in the upper levels and the divergence occurs in the lower levels, so very few air particles can reach into southern area. On the contrary, the south-west monsoon becomes stronger in the extreme wet event. The southwest monsoon can carry more water vapor. The upper levels show the divergence and the lower levels show the convergence, thus, more air particles can reach into the northern area.

\subsection{Moisture source and sinks}

The particle trajectory diagram shows the path of the air parcel in the target period and the change in specific humidity during the movement process, but this diagram is only a qualitative expression and does not give an accurate quantitative expression of the corresponding water vapour source. Therefore, the abovementioned method of identifying the source of water vapour was applied, and the specific humidity information during the particle movement process was gridded on a $1^{\circ} \times 1^{\circ}$ latitude and longitude grid to obtain the distribution of potential vapour sources and the evaporation intensity. This study selected a period ranging from 1999 to 2020, an SPI of -2.22 (March 2003) as the extremely dry period, 0.09 (April 2008) as the normal period, and 2.44 (July 2012) as the extremely wet period to analyse the distribution and intensity of potential sources of vapour evaporation in the three-river source region during different periods.

In Fig. 7, the warm colour represents the water vapour source, and the cool colour represents the sink. The darker the colour is, the greater the potential evaporation intensity is. Fig. 7(a) shows that when the drought index showed an extremely dry state, the water vapour source was not on the Qinghai-Tibet Plateau but on the south and west sides of the edge of the Qinghai-Tibet Plateau, along the southern foot of the Himalayas-Hengduan Mountains and mainly concentrated in the area northwest of the Ganges Plain - the Kashmir region between China, India and Pakistan. Other sources were in western and eastern Nepal, as well as Bhutan, northeastern India, and southern Motuo on the Qinghai-Tibet Plateau. In

Page $11 / 21$ 
addition to the three-river source region, the sink region was also distributed in the southern Tibetan Plateau and northern India. When the drought index indicated a normal state (Fig. 7(b)), the water vapour source was still concentrated in the southern foothills of the Himalayas and the Hengduan Mountains, but the intensity was quite different from that in the dry period. Among them, the evaporation intensity in the Kashmir region decreased in comparison with that in the dry period, while the intensity in Nepal and Bhutan increased. Except for the decrease in the Kashmir region, the area of evaporation sources in other regions showed an increasing trend. In addition, there were also sporadic evaporation sources in China's Sichuan Basin, three-river source region, Tarim Basin on the north side of Kunlun Mountains, Altun Mountains and Qaidam Basin, as well as the Northern Tibetan Plateau on its south side, which indicated that these two regions also contributed to the water vapour transport of the three-river source region. When the drought index showed an extremely wet state (Fig. 7(c)), the area and intensity of the water vapour source increased significantly compared with the other two cases. Water vapour sources were mainly distributed in the southern foothills of the Himalayas-Hengduan Mountains, three-river source region, northern Bay of Bengal, Indian Peninsula, Sichuan Basin-Qinling Mountains, Yunnan-Guizhou Plateau, Qilian Mountains- Loess Plateau, the middle and lower reaches of the Yangtze River, eastern and southern China, and northern part of the South China Sea. In addition, the entire Qinghai-Tibet Plateau also had a large area of potential water vapour sources, including the Tarim Basin on the north side of the Kunlun Mountains, Altun Mountains, Qaidam Basin and the Northern Tibetan Plateau on its south side, and the Pamirs Plateau, Iranian Plateau and Kunlun Mountains.

A comparison of the water vapour sources in the three periods showed that on the Qinghai-Tibet Plateau, the areas with high water vapour evaporation during the extremely wet period were mainly located in the southern foothills of the Himalayas and near the three-river source region and were generally biased towards the south and east of the Qinghai-Tibet Plateau. The water vapour sources in the northern plateau showed a scattered distribution. There were water vapour sources in the Altai Mountains and the Junggar Basin. The water vapour source in the Qilian Mountains and the Loess Plateau weakened during the normal period but nearly disappeared during the dry period, while the water vapour source in the Sichuan Basin-Qinling area strengthened during the extremely wet period. The water vapour source in the southern foothills of the Himalayas was very important in the three periods. Among them, the water vapour source of Kashmir strengthened immediately in the extremely wet period after weakening in the normal period, and the water vapour source on the west side of the Hengduan Mountains was the weakest during the extremely dry period. The water vapour sources in the Iranian Plateau, the Pamirs, the vicinity of the Bay of Bengal, the Indian Peninsula, the Yunnan-Guizhou Plateau-Hainan Island, the middle and lower reaches of the Yangtze River, and eastern and southern China gradually decreased and finally disappeared from the extremely wet period to the normal period and then to the extremely dry period.

The variation in water vapour source regions in different periods was related to the water vapour transport pathways. The east branch path and the south branch path played a leading role in the wet period, while the north branch path played a more important role during the dry period, and the oceans in the south and east basically had no water vapour sources in normal and dry periods. The evaporation intensity of water vapour sources on the south branch path and the east branch path, such as the middle 
and lower reaches of the Yangtze River, East China, South China, the Yunnan-Guizhou Plateau, and the Indian Peninsula, was high during the extremely wet period but was extremely weak and even disappeared during dry and normal periods. More specifically, the water vapour source in the Bay of Bengal increased during the wet period, which may be the result of abnormal anticyclones in the Bay of Bengal caused by the warming of the Arabian Sea (Sun et al., 2018).

\section{Discussion}

The three paths had different effects in different periods, which may be related to the circulation situation of the three-river source region in different periods. The source region of the Yellow River was an area affected by the westerlies and the monsoon. In rainy years, the westerly wind speed weakened, and the south water vapour transport of the southwesterly monsoon strengthened, which resulted in an increase in atmospheric water content in the three-river source region, while the drier years showed the opposite trend (Wang et al., 2006). In addition, in rainy years, the upper altitude of the source region was the divergence zone, and the lower altitude was the convergence zone, which formed a structure that was advantageous for the water vapour from the Bay of Bengal to transport continuously to the north. In contrast, in drier years, the upper altitude was the convergence zone, and the lower altitude was the divergence zone controlled by the lower airflow, which was not conducive to the transport of water vapour from the Bay of Bengal.

The spatial distribution of water vapour transport and the changes in potential source regions during regional extreme events were analysed using the drought index. The contribution of source evaporation to precipitation was not quantified, but Zhu (et al., 2019) analysed the evaporation contributions from different areas of the Yellow River source region in dry and wet years to the precipitation in the three-river source region and pointed out that the contribution of local evaporation in the three-river source region in dry and wet years was $22 \%$ and $11 \%$, respectively. In addition, it should be noted that this work focuses on the results from long-term monitoring of the soil moisture network and then obtains the drought index, the SPI, which can better reflect the occurrence of regional drought. However, errors are unavoidable in this work due to soil moisture hysteresis.

\section{Conclusion}

Based on the soil moisture observation data obtained by the PAW monitoring network in the QinghaiTibetan Plateau, this research has evaluated the applicability of the SPI in the three-river source region and captured the extremely dry, extremely wet and normal states in the three-river source region in the past 30 years. NCEP-FNL reanalysis data were adopted to drive the FLEXPART mode to simulate the trajectory of air parcels in extreme drought events, extreme wetness events and the normal state to analyse the spatial distribution of water vapour transport in the research area during the target period. The main conclusions are described as follows: 
(1) When the drought index was in an extremely dry and normal state, the water vapour in the research area mainly came from the north branch, including the water vapour from the Atlantic Ocean, northern Africa and European continent, passing through the mid-latitude Eurasian continent and entering the three-river source region from the west or north of the Qinghai-Tibet Plateau. The water vapour transport pathways in the normal period were more westerly. When the drought index was in an extremely wet state, the water vapour transport was mainly concentrated in the south branch and the east branch. The transport path of the south branch started from the water vapour in the Indian Ocean and the Arabian Sea, passed through the Indian Peninsula and the Bay of Bengal, and entered the three-river source region from the southwest side of the Qinghai-Tibet Plateau. The water vapour transport in the east branch came from the Pacific Ocean and the South China Sea and entered mainland China from the East/South China region through the Yangtze River Basin, entering the three-river source region from the east, south and west sides of the Qinghai-Tibet Plateau.

(2) During the periods of extreme drought, water vapour sources were mainly concentrated in Kashmir, the east and west sides of Nepal, and northwestern India. When the drought index was in a normal state, in addition to these areas, the water vapour sources were distributed in the Sichuan Basin-Qinling area, the Tianshan Mountains north of the Qinghai-Tibet Plateau, and the sources were even scattered further north in the Altai Mountains and the Junggar Basin. During the periods of extreme wetness, water vapour sources were mainly distributed near the Kunlun Mountains of the Qinghai-Tibet Plateau, the Iranian Plateau, the Pamirs, the southern foot of the Himalayas-Hengduan Mountains, the Sichuan Basin-Qinling Mountains, Qilian Mountains-Loess Plateau, the middle and lower reaches of the Yangtze River, East China, South China, the Indian Peninsula and the northern Bay of Bengal. By comparing the water vapour sources in the three periods, the water vapour sources in the southern foothills of the Himalayas were strong in all three periods, and the water vapour sources on the Qinghai-Tibet Plateau were generally stronger and larger from the dry period to the wet period.

\section{Declarations}

\section{Author Declarations}

\section{Funding}

This study was supported by the Second Tibetan Plateau Scientific Expedition and Research (STEP) program (2019QZKK0105). The National Natural Science Foundation of China (42075065). The Fundamental Research Funds for the Central Universities (Izujbky-2021-kb02).

\section{Conflicts of interest/Competing interests}

The authors confirm that there are no conflicts of interest.

\section{Ethics approval/declarations}

No ethical issues involved. No ethics committee approval was required for this paper. 


\section{Consent to participate}

The authors declare that they have consent to participate.

\section{Consent for publication}

The authors have consented to the publication.

\section{Availability of data and material/ Data availability}

For download of the model, please link to https://www.flexpart.eu/

"Daily Data Set of Surface Climate in China (V3.0)" provided by the National Meteorological Data Service Center (http://data.cma.cn/).

\section{Code availability}

Will be available on reasonable request.

\section{Authors' contributions}

Rong Liu: Conceptualization, Funding acquisition Writing-original draft, Writing-review. Xin Wang: Data curation, Formal analysis, Project administration, Resources. Zuoliang Wang: Methodology, Resources, Validation.

\section{References}

1. Bothe O, Fraedrich K, Zhu X (2011) Large-scale circulations and Tibetan Plateau summer drought and wetness in a high-resolution climate model. Int J Climatol 31:832-846. https://doi.org/10.1002/joc.2124

2. Chen B, Xu XD, Yang S et al (2012) On the origin and destination of atmospheric moisture and air mass over the Tibetan Plateau. Theor Appl Climatol 110:423-435. https://doi.org/10.1007/s00704012-0641-y

3. Chen B, Xu XD, Zhao TL (2013) Main moisture sources affecting lower Yangtze River Basin in boreal summers during 2004-2009. Int J Climatol 33:1035-1046. https://doi.org/10.1002/joc.3495

4. Dong WH, Lin YL, Wright JS et al (2016) Summer rainfall over the southwestern Tibetan Plateau controlled by deep convection over the Indian subcontinent. Nat Commun 7:10925. https://doi.org/10.1038/ncomms10925

5. Dong YC, Li GP, Yuan M et al (2017) Evaluation of five grid datasets against radiosonde data over the eastern and downstream regions of the Tibetan Plateau in summer. Atmos 8:56. https://doi.org/10.3390/atmos8030056

6. Fremme A, Sodemann H (2019) The role of land and ocean evaporation on the variability of precipitation in the Yangtze River valley. Hydrol Earth Syst Sci 23:2525-2540. 
https://doi.org/10.5194/hess-23-2525-2019

7. Gimeno L, Stohl A, Trigo RM et al (2012) Oceanic and terrestrial sources of continental precipitation. Rev Geophys 50:RG4003. https://doi.org/10.1029/2012RG000389

8. Gimeno L, Nieto R, Drumond A et al (2013) Influence of the intensification of the major oceanic moisture sources on continental precipitation. Geophys Res Lett 40:1443-1450.

https://doi.org/10.1002/grl.50338

9. Halwatura D, Mcintyre N, Lechner AM (2017) Capability of meteorological drought indices for detecting soil moisture droughts. J Hydrol-Reg Stud 12:396-412. https://doi.org/10.1016/j.ejrh.2017.06.001

10. Hogg EH, Barr AG, Black TA (2013) A simple soil moisture index for representing multi-year drought impacts on aspen productivity in the western canadian interior. Agric For Meteorol 178:173-182. https://doi.org/10.1016/j.agrformet.2013.04.025

11. Huang D, Gao S (2018) Impact of different reanalysis data on WRF dynamical downscaling over China. Atmos Res 200:25-350. https://doi.org/10.1016/j.atmosres.2017.09.017

12. Kalisa W, Zhang JH, Igbawua T (2020) Spatio-temporal analysis of drought and return periods over the east african region using standardized precipitation index from 1920 to 2016 . Agric Water Manag 237:106195. https://doi.org/10.1016/j.agwat.2020.106195

13. Kirillin G, Wen LJ, Shatwell T (2017) Seasonal thermal regime and climatic trends in lakes of the Tibetan highlands. Hydrol Earth Syst Sci 21:1895-1909. https://doi.org/10.5194/hess-21-18952017.

14. Li S, Yao Z, Liu Z et al (2019) The spatio-temporal characteristics of drought across Tibet, China: derived from meteorological and agricultural drought indexes. Theor Appl Climatol 137:2409-2424. https://doi.org/10.1007/s00704-018-2733-9

15. Li Z, Xiao Z (2020) Analyze on the contribution of the moisture sources to the precipitation over midlow Lancang River nearby region and its variability in the beginning of wet season. Theor Appl Climatol 141:775-789. https://doi.org/10.1007/s00704-020-03228-x

16. Liu YW, Liu YB, Wang W (2019) Remote Sens Environ 220:1-18. https://doi.org/10.1016/j.rse.2018.10.026. Inter-comparison of satellite-retrieved and Global Land Data Assimilation System-simulated soil moisture datasets for global drought analysis

17. Liu R, Wen J, Wang X et al (2021) Case studies of atmospheric moisture sources in the source region of the Yellow River from a Lagrangian perspective. Int J Climatol 1-15. https://doi.org/10.1002/joc.7317

18. Mckee TB, Doesken NJ, Kleist J (1993) The relationship of drought frequency and duration to time scales Anaheim: Proceedings of the 8th Conference on Applied Climatology

19. Raziei T (2021) Revisiting the Rainfall Anomaly Index to serve as a Simplified Standardized Precipitation Index. J Hydrol 602:126761 https://doiorg/101016/jjhydrol2021126761

20. Salah Z, Nieto R, Drumond A et al (2018) A lagrangian analysis of the moisture budget over the fertile crescent during two intense drought episodes. J Hydrol 560:382-395 
https://doiorg/101016/jjhydrol201803021

21. Shen SJ, Xiao H, Yang HL et al (2021) Variations of water vapor transport and water vaporhydrometeor-precipitation conversions during a heavy rainfall event in the Three-River-Headwater region of the Tibetan Plateau. Atmos Res 264:105874 https://doiorg/101016/jatmosres2021105874

22. Sodemann H, Schwierz C, Wernli H (2008) Interannual variability of Greenland winter precipitation sources: Lagrangian moisture diagnostic and North Atlantic Oscillation influence. J Geophys ResAtmos 113: D03107 https://doiorg/101029/2007jd008503

23. Sun B, Wang HJ (2014) Moisture Sources of Semiarid Grassland in China Using the Lagrangian Particle Model FLEXPART. J Clim 27:2457-2474. https://doiorg/101175/JCLI-D-13-005171

24. Sun B, Wang HJ (2018) Interannual variation of the spring and summer precipitation over the three river source region in China and the associated regimes. J Clim 31:7441-7457. https://doiorg/101175/JCLI-D-17-06801

25. Trenberth KE (1999) Atmospheric moisture recycling: Role of advection and local evaporation. J Clim 12: 1368-1381 https://doiorg/101175/1520-0442(1999)01220C0;2

26. Wang KL, Cheng GD, Ding YJ et al (2006) Characteristics of Water Vapor Transport and Atmospheric Circulation for Precipitation over the Source Regions of the Yellow and Yangtze Rivers. J Glaciol Geocryol 1:8-14 https://doiorg/ 101016/S1003-6326(06)60040-X

27. Wu ZY, Lu GH, Wen L et al (2011) Reconstructing and analyzing China's fifty-nine year (1951-2009) drought history using hydrological model simulation. Hydrol Earth Syst Sci 15:2881-2894 https://doiorg/105194/hess-15-2881-2011

28. Xu XD, Tao SY, Wang JZ et al (2002) The relationship between water vapor transport features of tibetan plateau-monsoon "large triangle" affecting region and drought-flood abnormality of china. Acta meteorol sin 60: 257-266 https://doiorg/103321/jissn:0577-6619200203001

29. Xu K, Zhong L, Ma Y (2020) A study on the water vapor transport trend and water vapor source of the Tibetan Plateau. Theor Appl Climatol 140:1031-1042. https://doi.org/10.1007/s00704-020-03142-2

30. Zhang C, Tang QH, Chen DL (2017) Recent Changes in the Moisture Source of Precipitation over the Tibetan Plateau. J Clim 30:1807-1819. https:// doiorg/101175/JCLI-D-15-08421

31. Zhao Y, Xu XD, Liao L et al (2018) The severity of drought and precipitation prediction in the eastern fringe of the Tibetan Plateau. Theor Appl Climatol 137:141-152. https://doiorg/101007/s00704-0182564-8

\section{Figures}




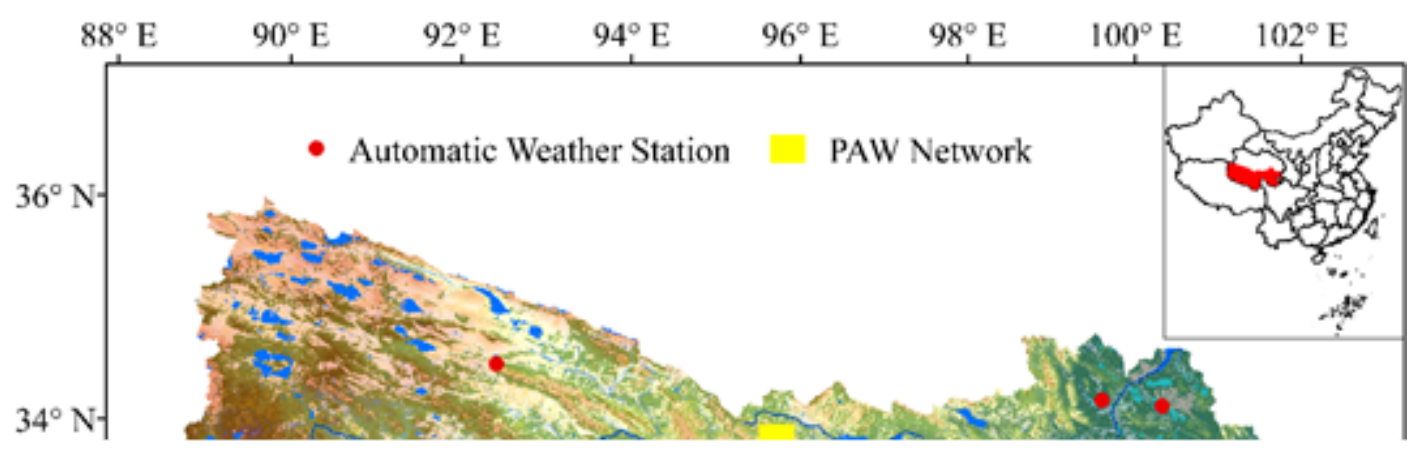

\section{Figure 1}

Location and landcover information of the source region of the three-river (the circles represent the automatic weather stations and the yellow squares represent the PAW networks)
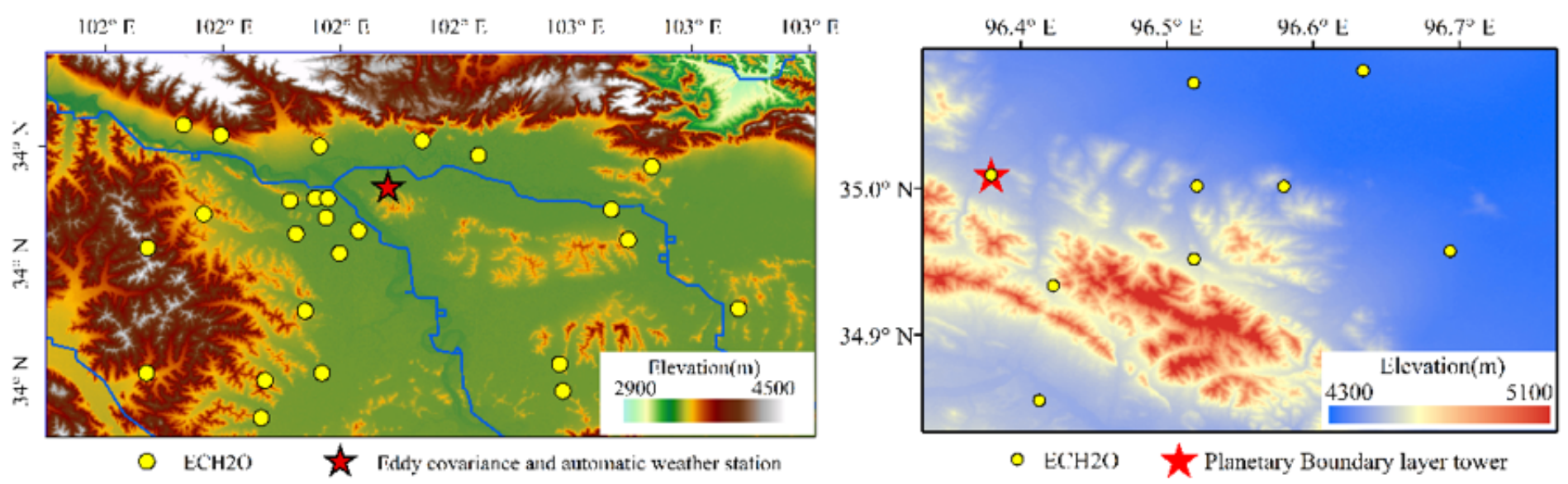

Figure 2

Location of the PAW moisture network and meteorological station (the circles represent the $\mathrm{ECH} 2 \mathrm{O}$ located and the stars represent the eddy covariance and planetary boundary layer tower) 


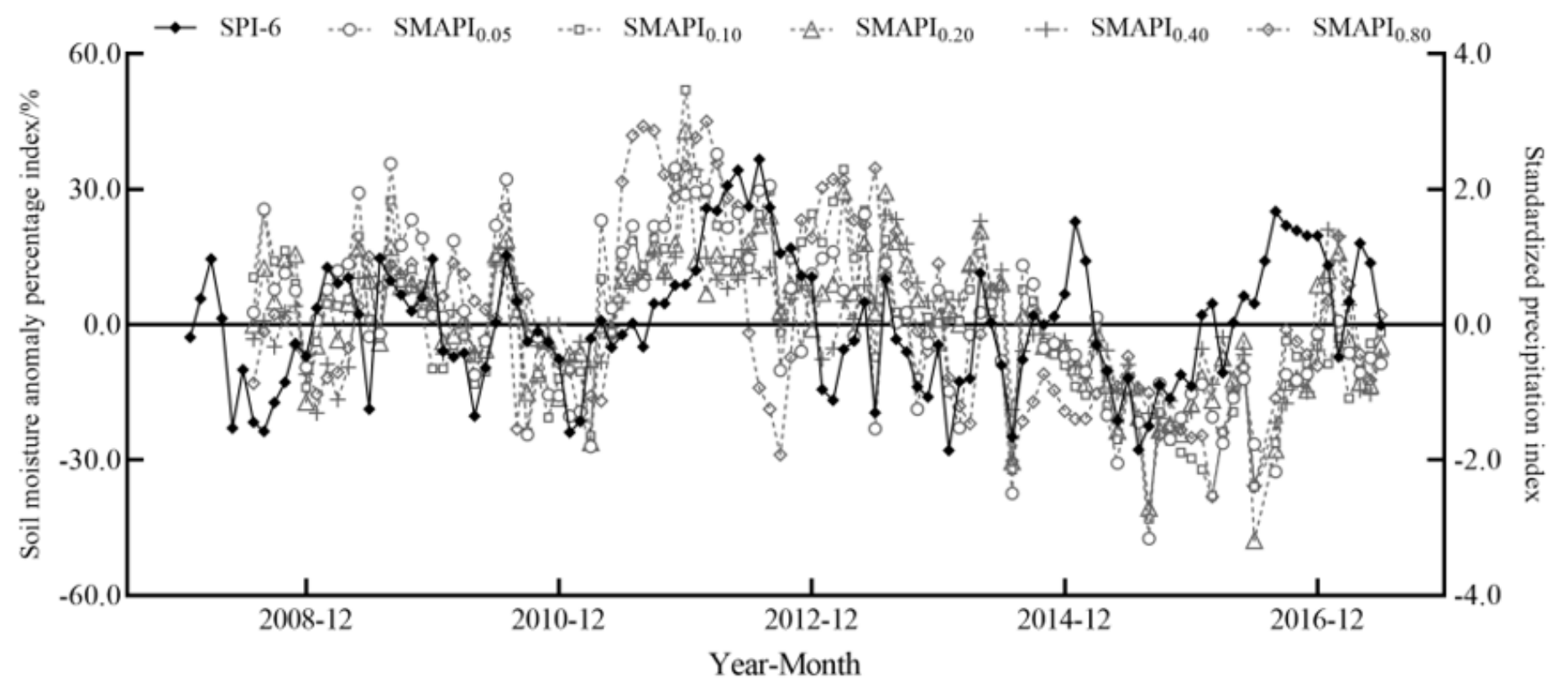

Figure 3

Time series of the SPI- 6 and SMAPI at different depths

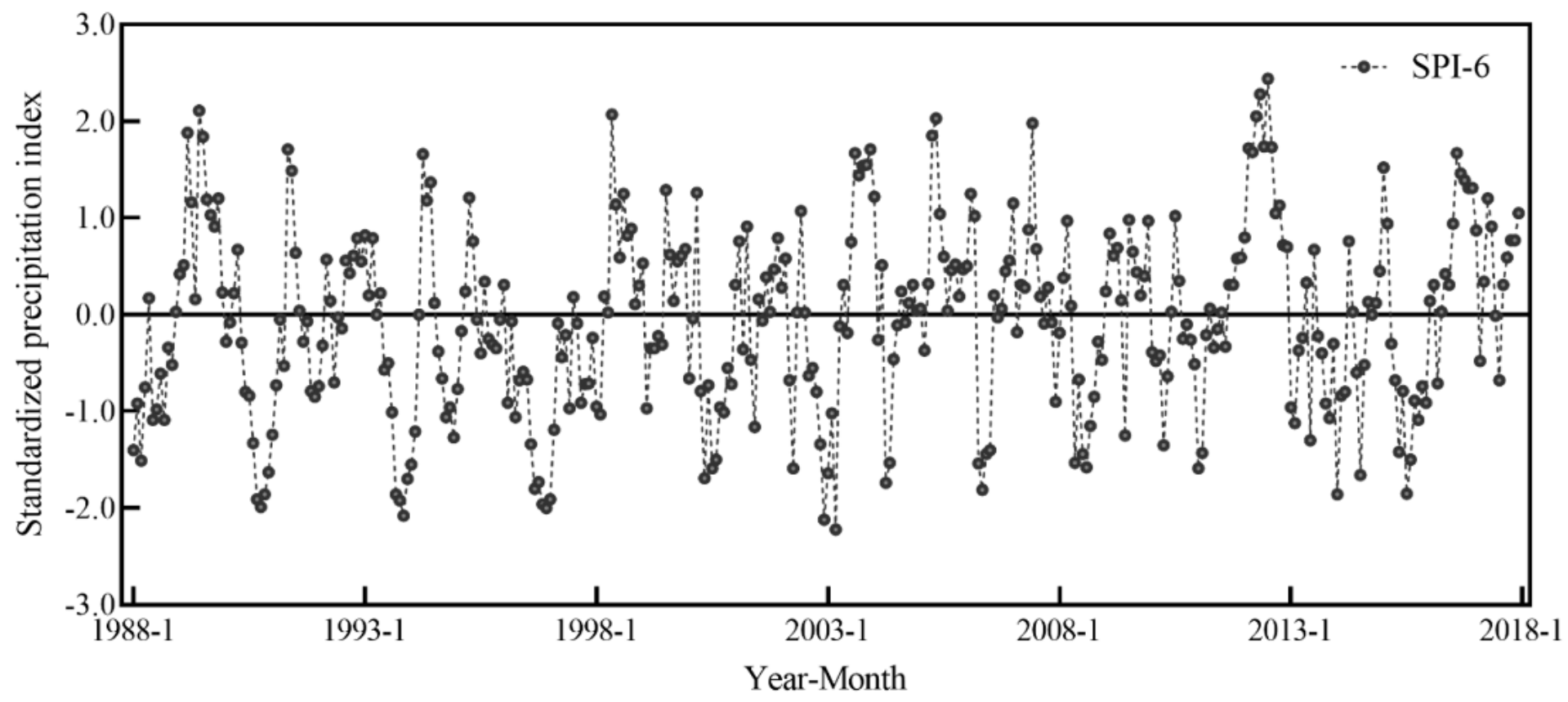

Figure 4

Temporal variation in the SPI-6 during 1988-2020 


\section{Figure 5}

Backward trajectories (1-10 days) of water vapour transport particles arriving at the target region under different drought indices. The track colour indicates the change in the specific humidity of gas [unit: $\left.\mathrm{g} \cdot(\mathrm{kg} \cdot 6 \mathrm{~h})^{-1}\right]$

\section{Figure 6}

Atmosphere circulations (500hPa) and Vapor flux (whole layer) of drought events $(a, b)$ and wet events (c, d) 
(a)

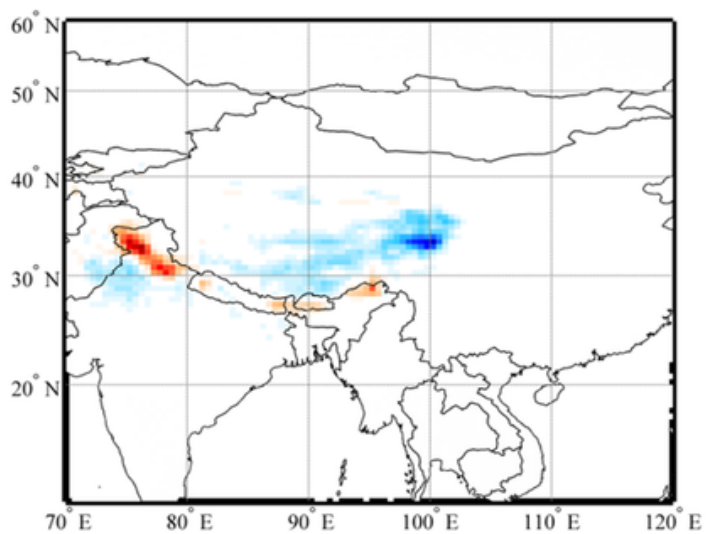

(b)

\section{Figure 7}

Distribution diagram of potential water vapour sources corresponding to different drought indices ((a) extremely dry, (b) normal, and (c) extremely wet) 